emissions from stationary boiler powerplants are being controlled was an interesting insight into other people's problems. The remaining papers in this section covered gas turbine, steam and Stirling-cycle powerplants for vehicles, with a fascinating one about the work of the General Electric Company (US) on the control and reduction of emissions from aero gas turbines. From this company's experience it would appear that the engine makers are on the last lap-reducing that reek of unburnt kerosene from idling engines which assails the passenger at every modern airport.

A very useful reference for any company technical library, or for a college -bearing in mind that much of the material will be out of date in five years - -but a trifle expensive for the individual's purse. JAMES HAY Stevens

\section{Madness and the Community}

A History of the Mental Health Services. By Kathleen Jones. Pp. xiii + 414. (Routledge and Kegan Paul: London and Boston, December 1972.) $£ 5$.

"History," said Henry Ford, "is bunk." In spite of Professor Kathleen Jones's modest supporting conclusion that the only lesson to be learned from the past is the unpredictability of change, her splendid book drives the reader relentlessly to a number of invaluable general deductions. Perhaps the most importait of these is that progress, seen in historical time, is advancing in spiral fashion, with the real forward movement along the axis being agonizingly slow compared with the apparent speed of advancement round the circle. A corollary of this is that the defects of one system of care are only too easily thought to be remediable by replacing it with a "new" system, which history reveals has already been tried and found to have its own defects.

This important book succinctly traces the evolution of attitudes to the mentally ill and the mentally handicapped through the documentary evidence available to the historian. What might otherwise be a dull catalogue of reformist speeches, parliamentary debating points, and successive legal enactments is brought to life by illuminating personal anecdotes. I am still haunted by the description of William Norris, who was confined continuously for nine years at Bethlem in a special iron apparatus which effectively prevented all but the smallest movements. On discovery in 1813, he was found to be quiet and rational, able to hold an intelligent conversation, and to read with comprehension. In case the reader is inclined to dismiss such extremities of treatment as belonging to the past, I would remind him that even today nursing shortages often compel staff to put violent patients in solitary confinement in small cells, when technical treatments well known to be effective in modifying such disturbed behaviour could be used if sufficient skilled staff were available.

No literate person should neglect a close examination of Professor Jones's book, for its lessons are of general importance. Perhaps all schools should make it their major study of social history. Imaginatively treated, its subject matter could make a strong impact on a new generation who might then make the sustained effort necessary to resolve the underlying problem: constructing a society with a different value system, in which the understanding of people's needs makes neglect of any section unlikely. We must remember that the weak and the poor are under-privileged because we are over-privileged. We have devised a set of rules for an economic competition which ensures that we inevitably win and they inevitably lose.

Community care is the currently favoured panacea for the evils of asylums built by a previous generation to rescue pauper lunatics from community neglect. The cynic will conclude, after reading this history, that it is possible to neglect the mentally disordered in two ways: we can shut them up in remote, impoverished institutions, or we can push them out into the uncaring anonymity of the urban environment. Either way we can assume it is for their good, especially if the service doesn't cost the rest of us too much and we don't actually have to be involved. And when some enterprising journalist uncovers a few scandalous cases, we can always comfortably indulge in moral indignation, especially if someone else can be conveniently scapegoated.

Community care, then, history tells us, is not worse, nor necessarily better, than institutional care. Care is the operative word. At a time when pride is being taken at the fall in the number of psychiatric beds, the number of people in prison and the number of urban homeless are rising. We can only be certain that the quality of life of the mentally disordered is improving, and goes on improving, relative to the rest of us, if we base our monitoring system on a complete case register which enables us to follow people's progress and to supply their needs through a flexible system of treatment and care facilities of a high standard. The public must not be allowed the comfort of ignorance, nor short-lived concern after scandalous revelations. They must be constantly reminded of the needs of local people and the cost of the provision of satisfactory services.

The problem can then be seen in its proper historical perspective-the mentally ill and the mentally handicapped are neglected by us. Unless we vote with our money, and personally befriend the disordered and the deviant, the next two hundred and fifty years will be much like the last.

The question this book poses is, do we care? JACK BAVIN

\section{Distributions}

Distributions in Statistics: Continuous Multivariate Distributions. By Norman L. Johnson and Samuel Kotz. Pp. 331. (John Wiley: New York and London, November 1972.) £7.50.

THIS is the fourth of a series in which the authors systematically review what is known about statistical distributions. The three earlier books dealt with discrete distributions and continuous univariate distributions (two volumes). This present volume, undoubtedly the toughest, completes the set; multivariate discontinuous distributions were covered in the first volume.

There is a sharp contrast between the wealth of mathematical forms with which we can express the frequency or probability distributions of univariate theory and the relatively few tractable forms available in multivariate theory. The number of parameters concerned increases alarmingly with the dimension of the distribution-even for the simplest case, the multivariate Gaussian (normal) form, the parameters increase as the square of the dimension number. The evaluation of numerical probabilities by integration is a formidable task even for two dimensions and even with the aid of the electronic computer. Some entirely new types of problem arise which are not encountered in univariate theory; for example, finding the distribution of the eigenvalues of a covariance matrix, which are not, unlike most statistics, algebraic functions of the observations. Altogether, the theory of multivariate distributions poses the most difficult problems in mathematical statistics.

One therefore gives an unqualified welcome to this book, which systematically reviews the present state of knowledge and pulls together a somewhat scattered literature in a consecutive development. As a textbook it would be heavy going except for the specialist. As a work of reference it is invaluable -over 700 titles are given. A comprehensive coverage of such a kind is to some extent a labour of love and statisticians everywhere should be grateful to the authors for the amount of effort which has gone to the completion of this work.

M. G. KenDALL 